\title{
A Case Report and Literature Review of Fetus in Fetu - A Rare Aberration of Embryogenesis in a 22-month-old Infant*
}

\author{
Ma. Femie Japitana, Josefa Hilado, Lysa Lynn Libanan \\ West Visayas State University Medical Center, Iloilo City, Philippines
}

\section{ABSTRACT}

Fetus in fetu (FIF) is an uncommon pathology resulting from an abnormal embryogenesis occurring in a diamnionic, monochorionic twinning during pregnancy. It is so rare that there is only one underdocumented case reported in the Philippines. We are faced with a curious case of a 22 -month old male child who presented with a gradually enlarging abdomen, diagnosed as FIF as confirmed by radiologic studies. After undergoing the necessary laboratory and radiologic work-ups, the patient was stabilized and eventually cleared for surgery. He underwent exploratory laparotomy with excision of FIF, from which a fetoid structure was recovered. Thorough gross and further radiologic evaluation of the recovered fetoid structure reveals findings that fulfilled the diagnostic criteria of a FIF.

Key words : fetus-in-fetu, teratoma, intra-abdominal mass, fetoid

ISSN 0118-3265

Printed in the Philippines.

Copyright $\odot 2017$ by the PJP

Received: 13 September 2016

Accepted: 1 November 2016.

Published online first: 13 December 2016.

https://doi.org/10.21141/PJP.2017.006

Corresponding author: Ma. Femie P. Japitana, MD

E-mail: femiejapitana@gmail.com

* This case has been qualified and was presented as a poster during the Philippine Society of Pathologists' 65th Annual Convention at the Edsa Shangri-La Hotel last April 27-29, 2016.

\section{INTRODUCTION}

The term "fetus in fetu" (FIF) was first used by Johann Friedrich Meckel during the late 18 th century. ${ }^{1}$ Subsequently, Willis described it as a rare condition where a malformed parasitic twin resides in the body of its host, usually in the host's abdominal cavity. ${ }^{2}$ The incidence is about 1 in 500,000 births and only about 100 cases of FIF have been reported to date. ${ }^{3}$ In the Philippines, only one case of FIF was reported in August of 2007. ${ }^{4}$ The majority of FIF cases presents as a retroperitoneal mass ${ }^{5-7}$ while others are seen in the sacrum and sacrococcygeal area $a^{5,6}$ and rarely within the cranium. ${ }^{8}$ Other reported cases show FIF existing within a teratoma. ${ }^{6}$

The condition represents an aberration of monozygotic diamniotic twinning where the unequal division of the totipotent inner cell mass of the developing blastocyst leads to the inclusion of a smaller cell mass within a maturing sibling embryo. It is supposed to be a highly differentiated form of teratoma. ${ }^{9}$

However, in view of the fact that body parts can be identified within it, there is a tendency to consider this condition as being distinct from a teratoma. It has been suggested that if spinal elements are absent, the lesion is a teratoma, whereas if they are present the tumor can be considered to be a FIF. ${ }^{10}$

This rare phenomenon, being the second reported and the first well-documented incident of FIF in the Philippines, as well as the importance of differentiating it from a teratoma, makes it a reportable case for which it is now presented.

\section{CASE}

This is a case of a 22-month-old infant who presented with a gradually enlarging abdomen, which started at the age of 3 months. An initial ultrasound of the whole abdomen was done at 4 months of age, revealing a thick-walled, cystic mass at the right upper abdomen, suspected to be hepatic in origin. The age of the patient and the initial ultrasound findings lead to an initial consideration of Hepatoblastoma. The patient was then lost to follow-up. However, due to a progressively enlarging abdomen, the patient and his mother came back and sought consult with a private physician 
wherein a second whole abdominal ultrasound was requested and revealed FIF.

The patent was subsequently admitted. Pertinent laboratory tests such as Beta HCG, CEA and AFP levels are all within normal range.

Thorough physical examination reveals a distended abdomen with an abdominal girth of $54 \mathrm{~cm}$ (Normal: $50 \mathrm{~cm}$ ).

A firm abdominal mass was palpated at the right upper quadrant, hence, a CT Scan was requested. The scan reveals a huge complex intraabdominal mass with septations, calcifications, long bones and axial skeleton, highly considering Fetus in Fetu (Figure 1). After being cleared, the patient underwent exploratory laparotomy with incidental appendectomy and excision of FIF.

Intraoperative findings reveal a large retroperitoneal mass measuring $9.4 \times 10.7 \times 9 \mathrm{~cm}$ attached to the mesentery along with its feeding vessels. The mass was excised and opened, revealing a thick-walled cyst containing a fetoid structure measuring 750 grams, entirely covered by thick vernix caseosa. The vernix was wiped off, revealing that the specimen is entirely covered with skin, and shows several structures resembling poorly-formed body parts.

The fetoid structure consists of a partially-formed head lacking a well-formed cranium and brain (anencephalic) (Figure 2). It measures $21 \mathrm{~cm}$ in circumference and is partially covered with fine black hair. There is a partially-formed structure resembling the right eye, a small mid-line protrusion resembling a nose and a wide slitlike opening which are presumed to be the optic placodes, nasal placode and the unfused brachial apparatus respectively. A few teeth are noted under the nasal placode. The trunk measures $30 \mathrm{~cm}$ in circumference and shows a tan, sac-like structure, measuring $3 \times 3 \times 2.3 \mathrm{~cm}$, resembling an omphalocoele protruding out of the

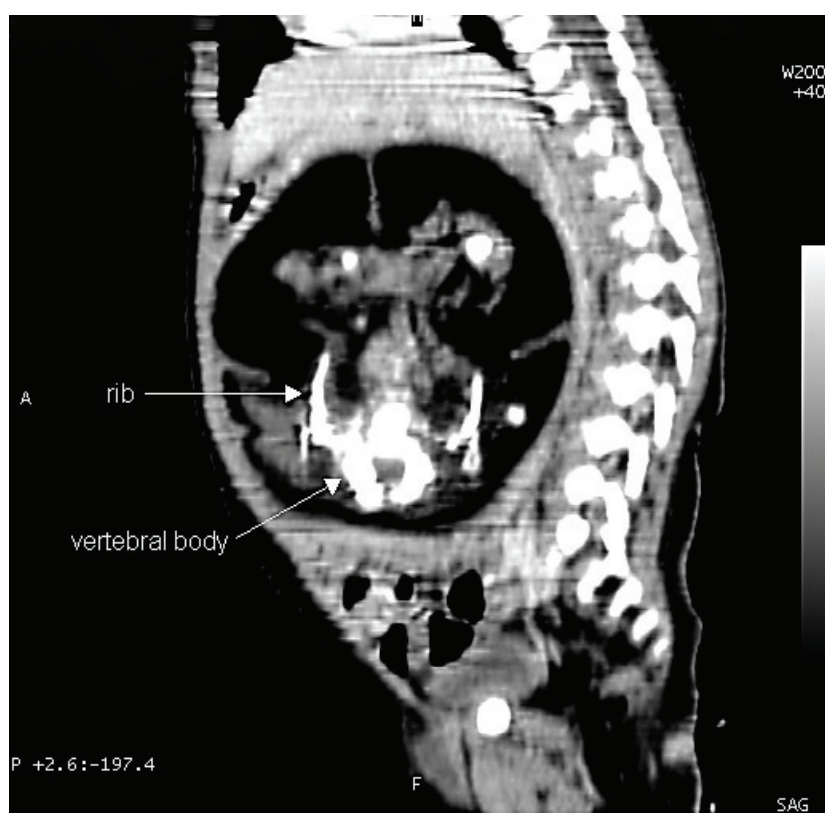

Figure 1. Computed tomography, sagittal view, depicting a huge, complex and septated intrabdominal mass with opacities representing the vertebral body and rib. chest. The chest and the trunk were opened and the sac was noted to be an extension of the peritoneal cavity which contains a coiled tubular structure measuring $7 \mathrm{~cm}$ long, resembling a primitive gut. At the center of the pelvic area is a structure measuring $4 \mathrm{~cm}$ long and $7 \mathrm{~cm}$ in circumference, with a rounded tip showing a meatal opening, resembling a poorly-formed penis (phallus). The meatal opening was cannulated into the urethra and revealed absence of continuation into the peritoneal cavity. Bilateral limb buds resembling upper and lower extremities with absence of wellformed digits are seen. The posterocaudal area shows a gluteal cleavage with imperforate anus. Further dissection reveals presence of a fused vertebral column housing an underdeveloped spinal cord. Abundant adipose tissues, as well as cartilaginous and bony tissues are likewise seen in other areas.

Pertinent histologic findings confirm that the thick-walled cyst and the external surface of the fetoid structure are composed of skin tissue consisting of keratinized stratified squamous epithelium and adnexal structures such as sweat glands, sebaceous glands and hair follicles. The right optic placode are lined by eroded corneal epithelium with scattered melanocytes and occasional acinar-like structures resembling lacrimal glands. The primitive gut is lined by intestinal epithelium. The urethra is lined by urothelial cells. The spinal reveal a central canal lined by pseudostratified cuboidal to columnar epithelium. The surrounding gray matter is poorly delineated and contains several multipolar motor neurons, scattered microglia and a few lymphocytes. The white matter contains a few poorly formed axons. Mature adipose tissues, cartilage and bone are likewise seen. There are no immature components seen in the sections examined.

Post operatively, the patient had an uneventful course in the wards and was discharged as soon as he was convalescent. Follow-up appointments at the Outpatient Department was done and revealed that the patient has improved appetite and has gained weight.

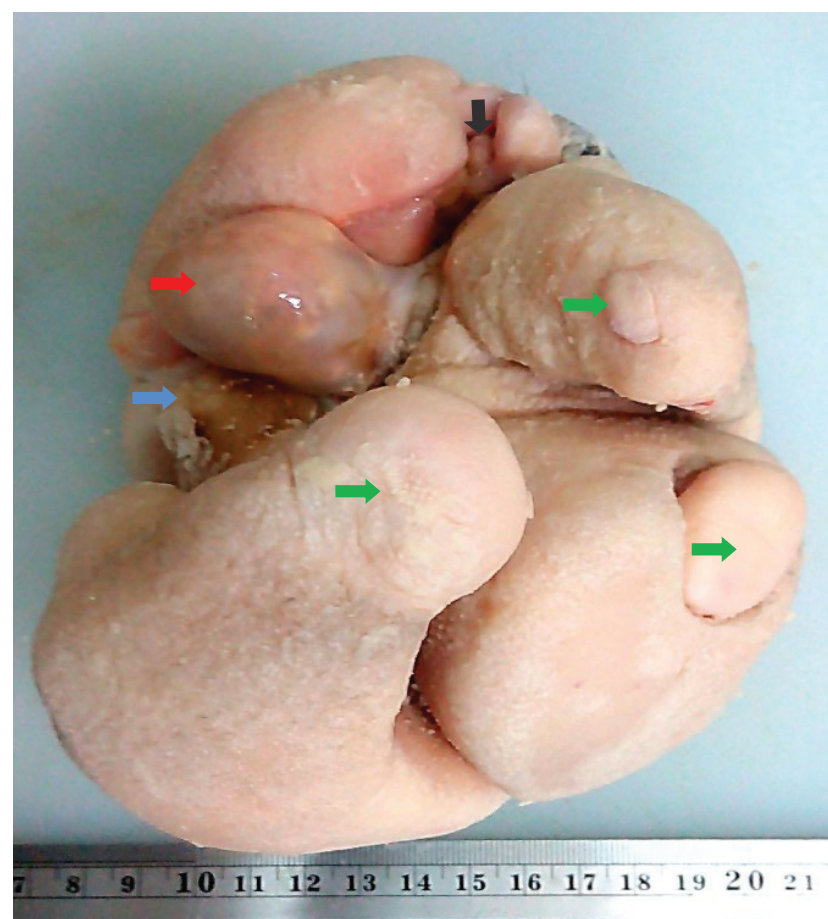

Figure 2. A fetoid structure showing a midline, unfused slit-like structure (black arrow) presumed to be the brachial apparatus; three out of four limb buds (green arrows); the inferior surface of the phallus (blue arrow); and a sac-like structure (red arrow) containing the primitive gut. 


\section{DISCUSSION}

Fetus in fetu is defined by the presence of one or more of the following characteristics: (1) it is enclosed within a distinct sac; (2) it is partially or completely covered by normal skin; (3) it has grossly recognizable anatomic parts; and (4) it is attached to the autosite by a pedicle containing a few relatively large blood vessels. On the other hand, teratoma consists of a chaotic mixture of tissues, which are also found within the body of the autosite, but it has the following characteristics: (1) it is enclosed in connective tissue; (2) it is broadly attached to the surrounding tissue; and (3) it is capable of independent growth or malignant behavior. ${ }^{11}$

Our case fulfilled the diagnostic criteria of fetus in fetu on sonography and pathologic examination. On pre-operative CT scan, there was an anencephalic acardiac mass with identifiable ribs, extremities and spine within an intraabdominal cystic mass (Figure 1). Autopsy findings revealed a solid mass with immature upper extremities and spine inside a fluid-filled sac. Microscopic evaluation of the solid mass had the general tissue characteristics of Fetus in Fetu, with right optic placode, primitive gut, underdeveloped spinal cord and urethra.

This case had an initial presentation of progressive abdominal enlargement of the right upper quadrant in a 22-month-old infant. The major presenting complaint is a palpable abdominal mass, predominantly in upper abdomen. ${ }^{12}$ Few reports describe antenatal diagnosis of FIF. Preoperative diagnosis can be made on plain radiographs and CT scan/MRI. The presence of vertebrae, long bones, bones of hands and feet etc are the common radiological findings. Visualization of a non-homogenous mass with bones especially vertebrae is considered pathognomonic of FIF. Failure to visualize vertebrae however does not rule out possibility of FIF. The other frequent differential is teratoma. ${ }^{13-1,5}$

The fetus is always anencephalic, the vertebral column and the limbs are present in the fetus in fetu in almost all cases $(91 \%$ and $82.5 \%$, respectively). ${ }^{16}$ The lower limbs are more developed than the upper limbs. Fetus in fetu was rarely found in the central nervous system, gastrointestinal tract, vessels, or the genitourinary tract; however, it was found in $55.8 \%, 45 \%, 40 \%$ and $26.5 \%$ of cases, respectively. It was rarer still to find fetus in fetu in the lungs, adrenal glands, pancreas, spleen, and lymph nodes. The heart was very rarely found in fetu.17 Patient in this case was male, anencephalic and acardic with a right optic placode, primitive gut, underdeveloped spinal cord and urethra. There is no definite data that states the number of FIF with phallus, however, two cases reported its presence.

Serum AFP and BHCG may be normal in most cases or occasionally elevated..$^{18}$ One case reveals elevation of both tests. In this patient, both are within normal range.

FIF is usually overlooked in the differential diagnosis of a newborn abdominal calcification. Clinically, FIF can be differentiated from teratoma by the presence of vertebral bodies and limbs. The presence of vertebral bodies not only means that the FIF passed the primary stage of gastrulation, but also may reflect its derivation from a primitive streak. The formation of the primitive streak normally starts during the 3rd week, together with gastrulation that will lead to the notochord formation and subsequently to the vertebral column and segmental axis. Therefore, FIF likely arises from a zygote at a primitive-streak stage and fetoid mass develops to a certain degree in a manner similar to normal fetal development. ${ }^{19}$
In our patient, pathologic examination showed vertebral column within the mass, further supporting the diagnosis of FIF. ${ }^{20}$

The recommended treatment for FIF is surgical excision. Because the final diagnosis of FIF is not made until pathological analysis, all parts of the mass should be removed to prevent malignant recurrence.

Although the prognosis for FIF is more favorable than for cystic teratoma, the presence of immature elements nevertheless indicates the need for close clinical and radiological follow up.

\section{CONCLUSION}

In conclusion, FIF is a rare and interesting entity that typically presents as an abdominal mass in infancy or early childhood. It can be diagnosed in the preoperative period through imaging techniques. Complete excision of the mass is curative and confirmatory. Though a rare entity, it should be kept in mind as a differential diagnosis for any abdominal mass in infancy and early childhood and must be differentiated from teratoma, since teratomas have a possibility to develop malignancy.

\section{ACKNOWLEDGMENTS}

The authors extend their heartfelt gratitude to their mentors in the Department of Pathology and Clinical Laboratory, as well as their colleagues in the Surgical and Pediatric Departments, who worked with them as a multidisciplinary team in the field and aided them with insights in order for this case to be published. Thank you very much Dr. Ansarie P. Salpin, DPSP, Dr. Noel G. Binayas, FPCS, FPSPS, Dr. Carlo Angelo C. Bordon and Dr. Anne Bernadette B. Arangcon.

\section{AUTHOR DISCLOSURE}

The authors declared no conflicts of interest.

\section{REFERENCES}

1. Magnus KG, Millar AJW, Sinclair-Smith CC, Rode $\mathrm{H}$. Intrahepatic fetus-in-fetu: a case report and review of the literature. J Pediatric Surg. 1999;34(12):1861-4. https://doi. org/10.1016/S0022-3468(99)90333-0.

2. Senyüz OF, Rizalar R, Celayir S, Öz F. Fetus in fetu or giant epignathus protruding from the mouth. J Pediatr Surg. 1992;27(12):1493-5. https://doi.org/10.1016/0022-3468 (92)90480-U.

3. Borges E, Lim-Dunham JE, Vade A. Fetus in fetu appearing as a pre-natal neck mass. J Ultrasound Med. 2005;24(9):13136. PMID: 16123193.

4. Fetus inside a baby; 'broken' food. GMA News Online. Posted August 1, 2007. http://www.gmanetwork.com/news/ story/53804/publicaffairs/fetus-inside-a-baby-broken-food.

5. Karaman I, Erdogan D, Ozalevli S, Karaman A, Cavusoglu YH, Aslan MK, et al. Fetus in fetu: a report of two cases. J Indian Assoc Pediatr Surg. 2008;13(1): 30-2. https://doi. org/10.4103/0971-9261.42572.

6. Ahmad Jan I, Al Hamoudi B, Shiniwas M. Fetus in fetu or teratoma: a report of four cases and literature review. Journal of Pediatric Surgical Specialties. 2015;9(1):1-52.

7. Murtaza A, Kanhaiva C, Sadhna M, Sabiha M. Fetus in fetu: a rare presentation in an adult female. OMJ. 2010;25. https:// doi.org/10.5001/omj.2010.43. 
8. Yang ST, Leow SW. Intracranial fetus-in-fetu: CT Diagnosis. Am J Neuroradiol. 1992;13(5):1326-9.

9. Willis RA. The borderland of embryology and pathology. 2nd edition. Washington, DC: Butterworths; 1962:442-462.

10. Jeanty P, de Andrade Gonçalves LF, Silva SR. Fetus-infetu. Available from: http://www.thefetus.net. [cited on 2000 Sep 18].

11. Spencer R. Parasitic conjoined twins: external, internal (fetuses in fetu and teratomas), and detached (acardiacs). Clin Anat. 2001;14(6):428-44. https://doi.org/10.1002/ca.1079.

12. Singh S, Rattan K, Navtej, Gil M, Mathur SK, Sen R. Fetus-infetu presenting as acute intestinal obstruction. Indian J Pathol Microbiol. 2010;53(1):128- 9. https://doi.org/10.4103/03774929.59203.

13. Eng HL, Chuang JH, Lee TY, Chen WJ. Fetus in fetu: a case report and review of the literature. J Pediatr Surg. 1989;24(3):296-9. https://doi.org/ 10.1016/S00223468(89)80017-X.

14. Federici S, Ceccarelli PL, Ferrari M, Galli G, Zanetti G, Domini R. Fetus in fetu: report of three cases and review of the literature. Pediatr Surg Int. 1991;6(1):60- 5. https://doi. org/10.1007/BF00174889.
15. Kurdi AM, Al-Sasi OM, Asiri SM, Al-Hudhaif JM. Fetus-infetu. Imaging and pathology. Saudi Med J.2012; 33(4):444-8. PMID: 22485242.

16. Lord JM. Intra-abdominal foetus in foetu. $\mathrm{J}$ Pathol. 1956;72(2):627-41. https://doi.org/10.1002/path. 1700720230 .

17. Kim OH, Shinn KS. Postnatal growth of fetus-in-fetu. Pediatr Radiol. 1993;23(5):411-2. https://doi.org/10.1007/BF02011978.

18. Chua JHY, Chui CH, Sai PTR, Jacobsen AS, Meenakshi A, Hwang WS. Fetus-in-fetu in the pelvis: report of a case and literature review. Ann Acad Med Singapore. 2005;34(10):6469. PMID: 16382253.

19. Miura S, Miura K, Yamamoto T, Yamanaka M, Saito K, Hirabuki $\mathrm{T}$, et al. Origin and mechanisms of formation of fetus-in-fetu: two cases with genotype and methylation analyses. Am J Med Genet A. 2006;140A(16):1737-43. https:// doi.org/10.1002/ajmg.a.31362.

20. Gupta KG, Singhal P, Arya N. Fetus in fetu: a rare congenital anomaly. J Surg Tech Case Report. 2010;2(2): 77-80. https:// doi.org/10.4103/2006-8808.73621.

Disclaimer: This journal is OPEN ACCESS, providing immediate access to its content on the principle that making research freely available to the public supports a greater global exchange of knowledge. As a requirement for submission to the PJP, all authors have accomplished an AUTHOR FORM, which declares that the ICMJE criteria for authorship have been met by each author listed, that the article represents original material, has not been published, accepted for publication in other journals, or concurrently submitted to other journals, and that all funding and conflicts of interest have been declared. Consent forms have been secured for the publication of information about patients or cases; otherwise, authors have declared that all means have been exhausted for securing consent. 